Gall.-Average diameter, 15 to $25 \mathrm{~mm}$; length (on twig), about 20 to $30 \mathrm{~mm}$. Galls luster-like, irregular in shape, sometimes, rounded, cocks-comb-like in appearance, springing from the small stems which shoot out laterally from the twig or branch, or terminal portion of latter. Consisting of irreglar massed clusters of many aborted, deformed, greatly thickened and fleshy leaflets springing from the side stems; surrounding the twig or branch but not attached thereto, dark scarlet-red in color on all surfaces exposed to the sun, the under side when not so exposed being annually greenish and always lighter than the upper or exposed portions. Inside portions green. External surface of the gall extremely irregular in outline, the fleshy leaflets arranged in irregular cockscomb-like groups more or less pointed apically, the groups of leaflets longitudinally creased, appearing as though formed of many little columns set side by side and soldered together, much resembling groups of certain columnar crystals.

Described from 3 or 4 galls. The fleshy groups of leaflets contain irregular cavities within them. These, when opened the following spring, revealed only small pale brownish bodies attached to the walls inside. I am unable to suggest the order of insects to which the maker of this gall belongs. It may possibly be an acarid - perhaps a phytoptid.

Tardy wing-expansion in Callosamia.A few days ago I found, in Kensington, N. H., a small wild-cherry tree hung with cocoons of Callosamia Promethea to the number of seventy-five at least. On some twigs six or seven hung close together, all unusually large and light-colored. I cut off over thirty of them, and on June I2th I opened them, finding all good but one, in which the pupa had failed to cast the larvaskin, and so had died. One cocoon contained a $q$ on the point of emerging, the pupa-skin being broken in several places. I took out the half-emerged moth, removed the ragged pupa-skin, and the moth crawled to the top of my cage, and hung there, undeveloped, all day and all night. This morning, June $3^{\text {th }}$ at nine o'clock, its wings were still undeveloped, and I supposed it had been stunted by the unusual mode of emergence. At ten o'clock, however, the wings had expanded to nearly full size, and in half an hour more the moth was a fine specimen, fully developed, and unusually large !

I have never known the wings to expand so many hours after the moth had emerged.

\section{Brookline, Mass.}

Caroline G. Soule.

Entomological Notes. - Insect parasitism is admirably and suggestively treated in Pres. Riley's address to the Entomological society of Washington, just printed in its proceedings. It is worthy of the closest attention as a broad outline of the subject; by the introduction of fuller illustrative details it could easily be expanded into a volume and be a very welcome addition to our literature.

In the last part of the transactions of the Entomological society of London, Dr. David Sharp shows that ants stridulate by means of fine transverse lines on the middle of the dorsum of the third abdominal segment where it is rubbed by the edge of the preceding segment; these organs are usually present in the Ponerides and Myrmicides, but appear to be absent from the Camponotides and Dolichoderides.

A. D. Hopkins prints in Bull. $3^{1}$ of the West Virginia experiment station an interesting Catalogue of West Virginia Scotytidae and their enemies.

Wytsam of Bruxelles announces a new issue of Hübner's Sammlung exotischer schmetterlinge and Zuträge, 664 quarto plates in all, the plates copied by heliogravure and colored by hand; the original and the latest nomenclature will be added. It will appear in 60 equal parts and be sold for 500 francs, payable by parts. 


\section{The Butterflies of the Eastern United States and Canada.}

With special reference to New England. By SAmuel H. Scudder.

Illustrated with 96 plates of Butterflies, Caterpillars, Chrysalids, etc. (of which 4I are colored) which include about 2,000 Figures besides Maps and Portraits. I958 Pages of Text.

Vol. I. Introduction; Nymphalidae.

Vol. 2. Remaining Families of Butterflies.

Vol. 3. Appendix, Plates and Index.

The set, 3 vols., royal 8vo, half levant, $\$ 7.5 .00$ net.

HOUGHTON, MIFFLIN \& CO.,

4 Park St., Boston, Mass.

\section{FUST PUBLISHED.}

\section{Scudder's Brief Guide to the Com- moner Butterflies.}

By Samuel H. Scudder, author of "Butterflies of the Eastern United States and Canada,"etc. $\mathrm{xi}+206$ pp. I2mo. \$r.25.

An introduction, for the young student, to the names and something of the relationship and lives of our commoner butterflies. The author has selected for treatment the butterflies, less than one hundred in number, which would be almost surely met with by an industrious collector in a course of a year's or two year's work in our Northern States east of the Great Plains, and in Canada. While all the apparatus necessary to identify these butterflies, in their earlier as well as perfect stage, is supplied, it is far from the author's purpose to treat them as if they were so many mere postage-stamps to be classified and arranged in a cabinet. $\mathrm{He}$ has accordingly added to the descriptions of the different species, their most obvious stages, some of the curious facts concerning their periodicity and their habits of life. A short introduction to the study of butterflies in general is prefixed to the work, and is followed by a brief account of the principal literature of the subject.

\section{Scudder's The Life of a Butterfly. A Chapter in Natural History for the General Reader.}

By SAmuel H. Scudder. I86 pp. $16 \mathrm{mo}$. $\$ 1.00$.

In this book the author has tried to present in untechnical language the story of the life of one of our most conspicuous American butterflies. At the same time, by introducing into the account of its anatomy, development, distribution, enemies, and seasonal changes some comparisons with the more or less dissimilar structure and life of other butterflies, and particularly of our native forms, he has endeavored to give, in some fashion and in brief space, a general account of the lives of the whole tribe. By using a single butterfly as a special text, one may discourse at pleasure of many; and in the limited field which our native butterflies cover, this method has a certain advantage from its simplicity and directness.

$$
\begin{gathered}
\text { HENRY HOLT \& CO., } \\
\text { Publishers, } \\
\text { NEW YORK. }
\end{gathered}
$$

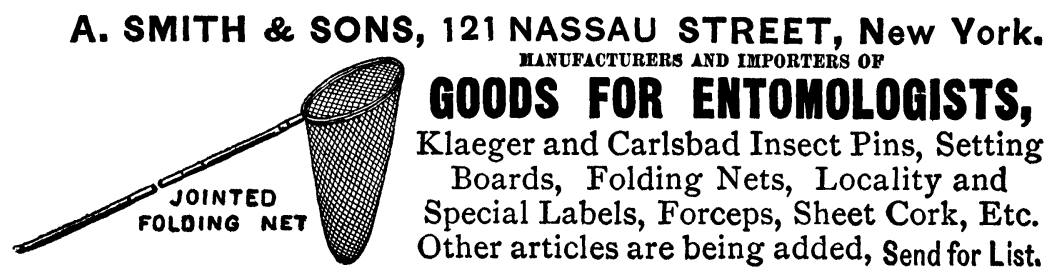



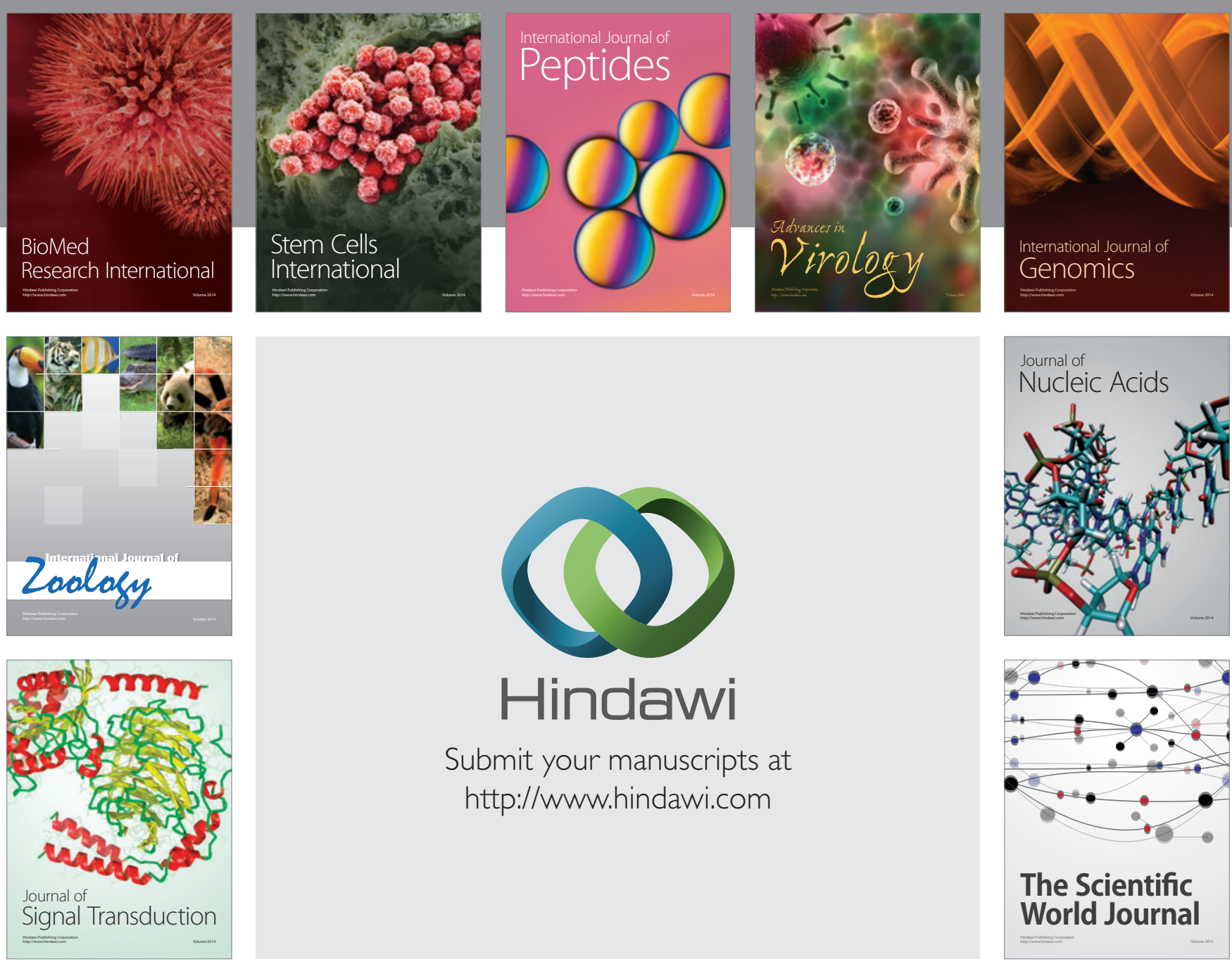

Submit your manuscripts at

http://www.hindawi.com
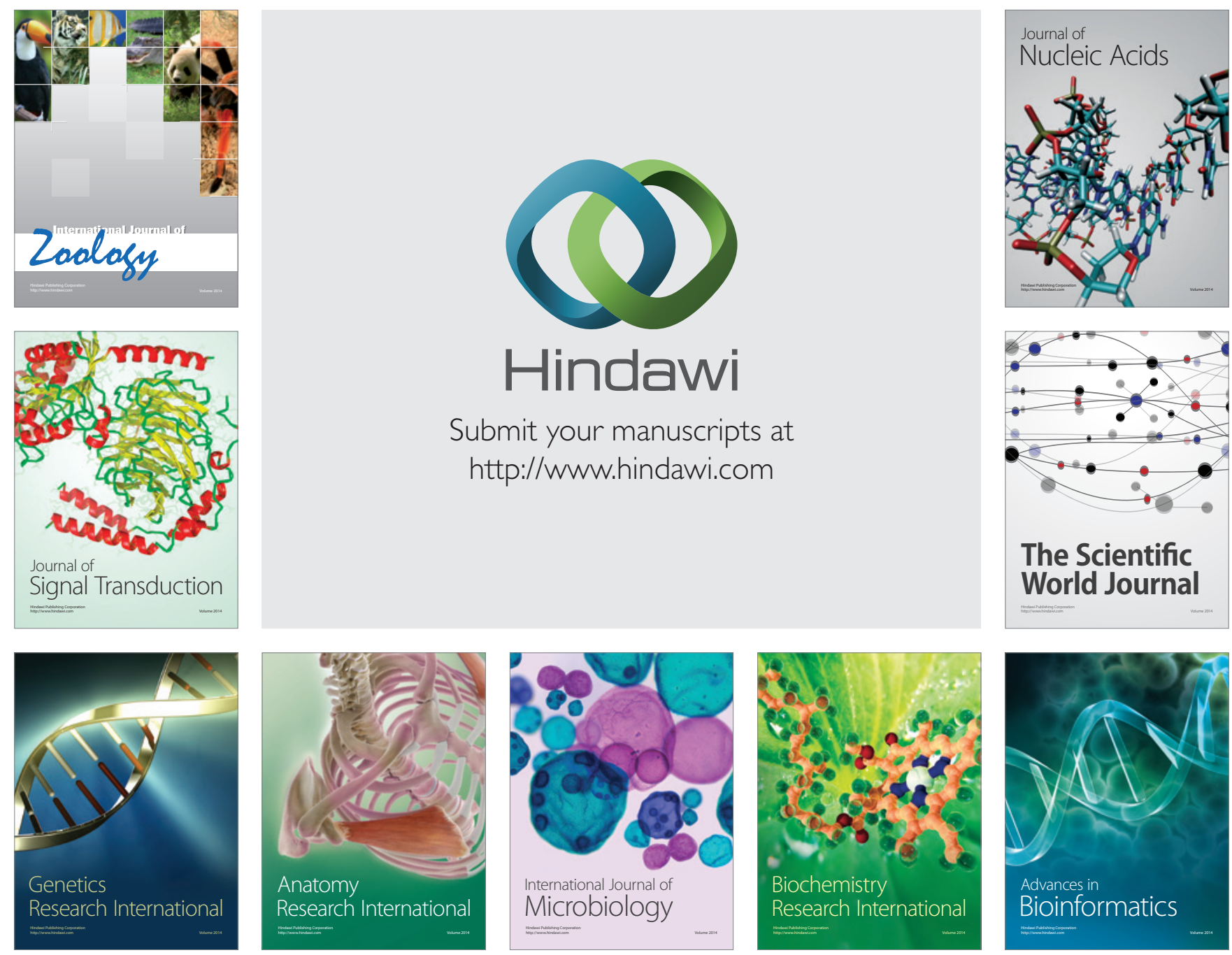

The Scientific World Journal
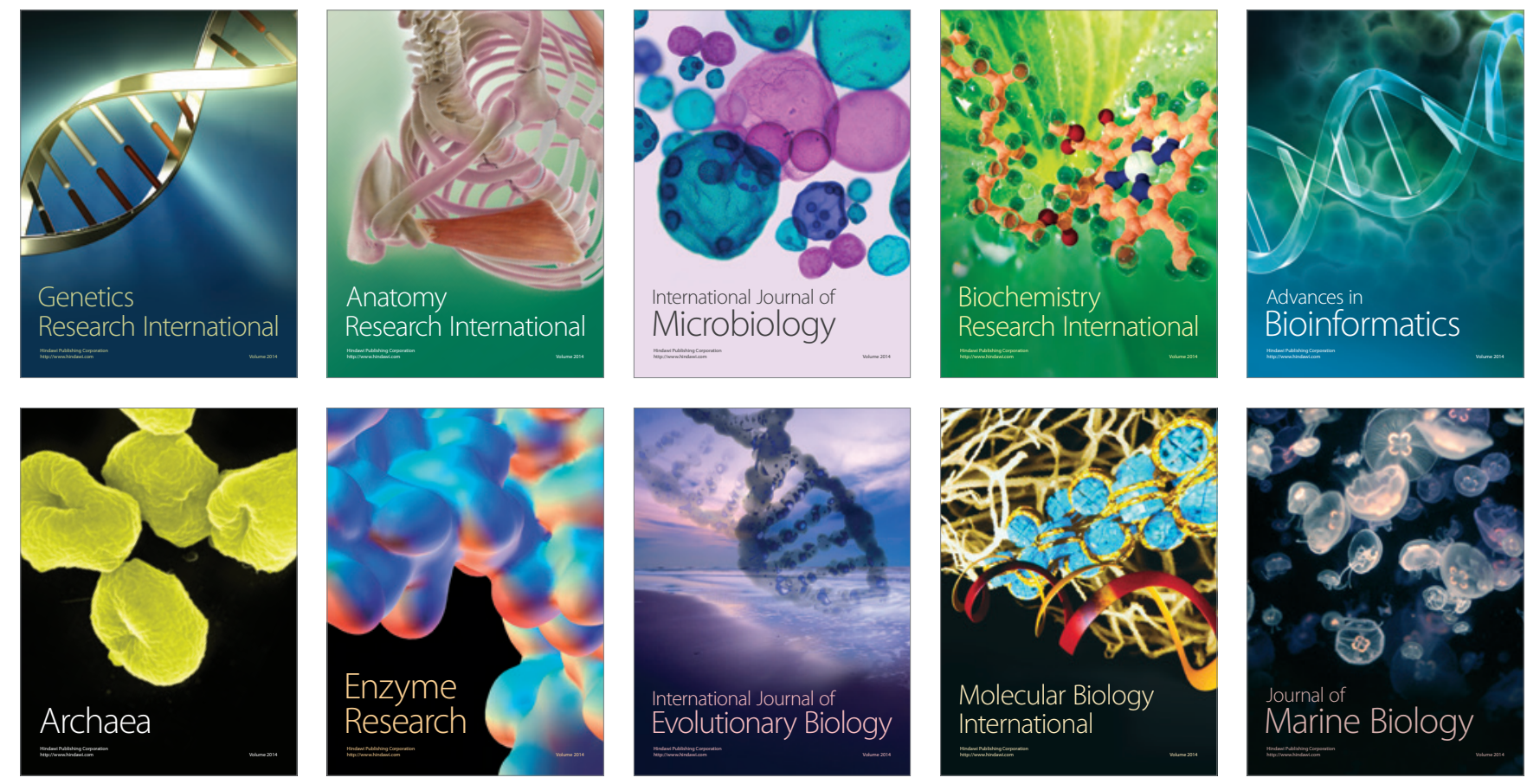